\title{
FIRST EVIDENCE OF TICK-BORNE PROTOZOAN PATHOGENS, BABESIA SP. AND HEPATOZOON CANIS, IN RED FOXES (VULPES VULPES) IN SERBIA
}

\author{
Salem JuwaID ${ }^{1}$, Ratko SukARA ${ }^{2}$, Aleksandra Penezić ${ }^{1}$, Darko MiHALJICA ${ }^{2}$, \\ Gorana VEINOVIĆ ${ }^{2}$, Nickolas G. KAVALLIERATOS ${ }^{3}$, Duško ĆIROVIĆ ${ }^{1}$ \\ and Snežana ToMANOVIĆ $\dot{2}^{*}$ \\ ${ }^{1}$ Faculty of Biology, University of Belgrade, Belgrade, Serbia; ${ }^{2}$ Department of Medical \\ Entomology, Center of Excellence for Food and Vector-borne Zoonoses, \\ Institute for Medical Research, University of Belgrade, Dr Subotića 4, P.O. Box 39, \\ 11129 Belgrade, Serbia; ${ }^{3}$ Laboratory of Agricultural Zoology and Entomology, \\ Faculty of Crop Science, Agricultural University of Athens, Athens, Greece
}

(Received 8 October 2018; accepted 15 February 2019)

Tick-borne haematozoans cause severe diseases in domestic animals, and some of them have zoonotic potential. The results of previous studies in Europe point to the important role of foxes in natural endemic cycles of several tick-borne pathogens, including protozoa. The aim of the present research was to acquire information on the prevalence and distribution of tick-borne protozoan parasites among foxes in Serbia. Legally hunted foxes from 14 localities throughout Serbia were analysed. Spleen samples were collected from 129 animals and tested for the presence of Babesia spp. and Hepatozoon spp. by PCR. In total, 79/129 (61.2\%) of the tested foxes were positive for $H$. canis, while the presence of two Babesia species was confirmed: B. vulpes $(37 / 129,28.7 \%)$ and B. canis $(1 / 129,0.8 \%)$. Coinfection with $B$. vulpes and $H$. canis was present in 26/129 (20.2\%) foxes and one animal $(1 / 129,0.8 \%)$ was co-infected by $B$. canis and $H$. canis. The results of this study indicate the important role of foxes in the epizootiology of $B$. vulpes and $H$. canis in the Republic of Serbia and stress the need for further research to clarify all elements of the enzootic cycle of the detected pathogens, including other reservoirs, vectors, and transmission routes. fox, Serbia

Key words: Babesia canis, Babesia vulpes, Hepatozoon canis, PCR, red

Tick-borne protozoan pathogens are the causative agents of severe diseases in domestic animals, and some of them have zoonotic potential as well (Solano-Gallego et al., 2016). They are maintained in nature in enzootic cycles that include ticks and different vertebrates as hosts. Thus, from the epizootiological point of view, knowledge about elements of the enzootic cycles of a particular

*Corresponding author; E-mail: snezanat@imi.bg.ac.rs; Phone: 00381 (11) 2685-788; Fax: 00381 (11) 2643-691 
pathogen in a given area is of great importance. The diseases caused by protozoa of the genus Babesia are highly important in domestic animals. Canine babesiosis in Europe is associated with four Babesia species: B. canis and B. vogeli (traditionally referred as 'large' babesial species); and B. gibsoni and B. microti-like ('small' babesial species) (Irwin, 2009). For B. microti-like, there is no formal valid description in accordance with the International Code of Zoological Nomenclature (James Harris, 2016), and numerous synonyms for this species exist in the literature, i.e., Theileria annae, Babesia 'Spanish dog isolate', Babesia annae, Babesia cf. microti, and the most recently suggested name Babesia vulpes sp. nov. (Baneth et al., 2015), which will be used below in order to avoid confusion. The occurrence of canine babesiosis in Europe is closely linked with the presence of tick species that parasitise domestic dogs, like Dermacentor reticulatus, Rhipicephalus sanguineus sensu lato (s.1.), Haemaphysalis sp., and Ixodes ricinus. The most common cause of canine babesiosis in Europe is $B$. canis and its presence in many European countries is related to the broad geographical distribution of the main tick vector, D. reticulatus (Petra et al., 2018). The second 'large' babesial species with clinical importance in European dogs, B. vogeli, is globally distributed (Irwin, 2009) and $R$. sanguineus s.l. is recognised as the main vector (Dantas-Torres and Otranto, 2015). Infection with $B$. vogeli can be subclinical but may also cause serious illness in infected dogs (Baneth, 2018). Babesia gibsoni is the most prevalent small Babesia species, with global distribution. It is associated with vectors from the genus Haemaphysalis, while H. bispinosa and $R$. sanguineus s.l. have been proposed as potential vectors (Baneth, 2018). Besides being vector-borne, for $B$. gibsoni vertical transmission and the possibility of direct infection by infected blood (e.g., through transfusion, fighting of dogs) has been proven (Birkenheuer et al., 2005). Babesia vulpes has been detected as a cause of canine babesiosis in several European countries (Miró et al., 2015). Epizootiological studies indicate that I. hexagonus, I. canisuga, I. ricinus, and $D$. reticulatus are candidates as vectors for B. vulpes (Najm et al., 2014). Babesiosis caused by $B$. canis and B. gibsoni has been described in Serbian dogs (Davitkov et al., 2015), while B. vogeli, B. vulpes, and the zoonotic but not canine pathogen $B$. microti were detected in healthy dogs using PCR (Gabrielli et al., 2015). Recently the DNA of B. canis (4.2\%) has been detected in golden jackals (Canis aureus) from Serbia (Sukara et al., 2018).

Hepatozoon canis is a haematozoan parasite widespread among domestic and wild carnivores in Europe. Infection with $H$. canis in dogs is commonly subclinical, but in predisposed animals it can lead to severe disease (Baneth, 2011). Autochthonous dog hepatozoonosis is present in many European countries with a Mediterranean climate (e.g. Turkey, Bulgaria, Greece, Croatia, Italy, Portugal) (Baneth, 2011), while high prevalence of $H$. canis has been detected in foxes all over Europe (Hodžić et al., 2015). In Europe, $H$. canis is transmitted mainly by $R$. sanguineus s.l. (Dantas-Torres and Otranto, 2015). The presence of $H$. canis 
in regions considered free of $R$. sanguineus s.l. suggests other (e.g. transplacental) transmission routes (Hodžić et al., 2018). So far in Serbia, the presence of $H$. canis has only been confirmed in a single healthy dog showing no clinical signs from the southern part of the country (Gabrielli et al., 2015).

Commonly, the same species of Hepatozoon and Babesia are found to infect wild canids and domestic dogs. Based on results obtained using an evolutionary approach, Penzhorn (2011) suggested that these haematozoan pathogens had been transmitted to dogs from wild canids. It therefore seems possible that these protozoan pathogens are transmitted by arthropod vectors from wild canids to domestic dogs in regions where ecological niches of wild and domestic canids overlap (Margalit Levi et al., 2018). In recent years, researchers across Europe have indicated the potential role of red foxes (Vulpes vulpes) as a reservoir for several tick-borne agents (Hodžić et al., 2015; Millán et al., 2016). Red foxes are the most widespread carnivore species in the world, widely distributed in the Northern Hemisphere and introduced elsewhere. They are highly adapted to living in anthropogenically modified habitats and appear to be closely associated with people. Today, increased numbers and densities of fox populations are documented in all European countries involved in rabies control programmes (including Serbia), since rabies virus has a great impact on the population dynamics of this species. With the recovery of European populations in rural regions, foxes established populations in major cities of countries in the continental part of Europe after the 1980s (Plumer et al., 2014). In Serbia, the range of foxes covers the whole territory of the country (Ćirović, 2000). In the countries bordering on Serbia, a relatively high prevalence of the haemoprotozoan parasites Babesia spp. and $H$. canis was confirmed by molecular methods in fox populations (Farkas et al., 2014, 2015; Hodžić et al., 2015). Research on the role of foxes in the epizootiology of $H$. canis and Babesia spp. has not been conducted so far in Serbia. Furthermore, there are no data on the prevalence of $H$. canis in other autochthonous wild canids (grey wolves, Canis lupus, and golden jackals, C. aureus) in Serbia. Therefore, the objective of the present study was to acquire information on the prevalence and distribution of Babesia spp. and H. canis among foxes in Serbia and evaluate the obtained results from the epizootiological point of view.

\section{Materials and methods}

Tissue samples were collected in co-operation with local hunters from legally hunted foxes over a period of seven years (2010-2016). In total, 129 animals were dissected and spleen samples were collected. The date of hunting, sex information, and location data were recorded for each fox sampled. All collected samples originated from 14 localities throughout Serbia (Fig. 1). The collected samples were transported at $4{ }^{\circ} \mathrm{C}$ to the Institute for Medical Research and stored 
in a freezer $\left(-80^{\circ} \mathrm{C}\right)$ up to DNA extraction. The DNA extraction was performed using the Gene Jet Genomic DNA Purification Kit (Fermentas, Thermo Scientific). A small portion of deep-frozen spleen tissue (up to $10 \mathrm{mg}$ ) was homogenised by micropestles (Eppendorf ${ }^{\mathrm{TM}}$ ), and the extraction was carried out according to the manufacturer's instructions. The extracted DNA was stored at $-20{ }^{\circ} \mathrm{C}$ until PCR analysis.

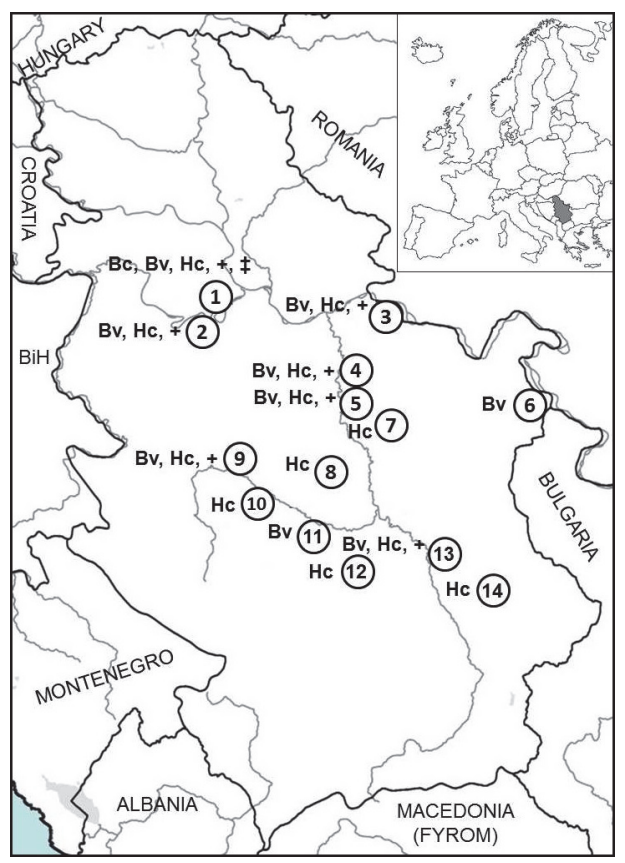

Fig. 1. Geographical distribution of foxes positive for, and co-infected with, Babesia vulpes, Babesia canis and Hepatozoon canis in the Republic of Serbia. 1 - Surčin, 2 - Obrenovac, 3 - Veliko Gradište, 4 - Velika Plana, 5 - Svilajnac, 6 - Negotin, 7 - Despotovac, 8 - Rekovac, 9 - Kraljevo, 10 - Vrnjačka Banja, 11 - Trstenik, 12 - Blace, 13 - Niš, 14 - Bela Palanka. Bc - Babesia canis, $\mathrm{Bv}$ - Babesia vulpes, Hc - Hepatozoon canis; +: co-infection with Babesia vulpis and Hepatozoon canis; + : co-infection with Babesia canis and Hepatozoon canis

\section{PCR assay}

Five individual randomly selected samples of the extracted DNA were combined into one pool. Whenever the pools were positive, the individual DNA samples were subjected to analysis. For initial detection of Babesia spp., we used the BabF (5'-GCGATGGCCCATTCAAGTTT-3') and BabR (5'-CGCCTG CTGCCTTCCTTAGA-3') primers to amplify a 146-bp fragment of the $18 \mathrm{~S}$ ssrRNA gene (Theodoropoulos et al., 2006). For all positive samples, further PCR assays were performed with the BJ1 (5'-GTCTTGTAATTGGAATGA TGG-3') and BN2 (5'-TAGTTTATGGTTAGGACTACG-3') primers for amplification of a larger fragment (408 bp) of babesial 18S rRNA gene (Casati et 
al., 2006). Detection of the DNA of Hepatozoon spp. in the tested samples was performed using the HepF for (5'-ATACATGAGCAAAATCTCAAC-3') and HepR_rev (5'-CTTATTATTCCATGCTGCAG-3') primers, which amplify the 666-bp fragment of the 18S ssrRNA gene (Inokuma et al., 2002). The PCR reactions used in screening spleens for Babesia spp. and Hepatozoon spp. were prepared using PCR Master Mix (2X) (Thermo Fisher Scientific Inc.) according to the manufacturer's instructions. Amplification of PCR products was performed in a Veriti Thermal Cycler device (Applied Biosystems).

In order to prepare Babesia spp. positive samples for sequencing, the BJ1 and BN2 primers were used in the present study. Amplifications were performed in a reaction mixture composed of $24.75 \mu 1$ of nuclease-free water, $10 \mu \mathrm{l}$ of $5 \mathrm{X}$ Reaction Buffer (7.5 mM MgCl2; pH 8.5), $1 \mu$ of dNTPs $(10 \mathrm{mM}), 0.250 \mu \mathrm{l}$ of Taq polymerase $(5 \mathrm{u} / \mu \mathrm{l}$, GoTaq G2 DNA Polymerase, Promega Corporation, USA), $4 \mu \mathrm{l}$ of each primer $(10 \mathrm{pmol} / \mu \mathrm{l})$, and $6 \mu \mathrm{l}$ of tested DNA. The amplification conditions were: initial denaturation step of $2 \mathrm{~min}$ at $95^{\circ} \mathrm{C}$, followed by 35 cycles of denaturation at $95^{\circ} \mathrm{C}$ for $1 \mathrm{~min}$, annealing at $54^{\circ} \mathrm{C}$ for $1 \mathrm{~min}$, and elongation at $72{ }^{\circ} \mathrm{C}$ for $1 \mathrm{~min}$. Final extension was at $72{ }^{\circ} \mathrm{C}$ for $5 \mathrm{~min}$. Samples positive for Hepatozoon spp. were prepared for sequencing using the primers HepF_for and HepR_rev, while the PCR reaction was set up in the same way as for Babesia spp. (GoTaq G2 DNA Polymerase, Promega Corporation, USA). Cycling conditions were $95{ }^{\circ} \mathrm{C}$ for $2 \mathrm{~min}, 35$ cycles of $95^{\circ} \mathrm{C}$ for $1 \mathrm{~min}, 57^{\circ} \mathrm{C}$ for $1 \mathrm{~min}$, and $72{ }^{\circ} \mathrm{C}$ for $1 \mathrm{~min}$; and final extension at $72{ }^{\circ} \mathrm{C}$ for $5 \mathrm{~min}$.

\section{Sequencing and sequence analysis}

The purification and Sanger sequencing of obtained amplicons were performed by a commercial laboratory (Macrogen, Amsterdam, The Netherlands). The resulting sequences were processed in the FinchTV software (ver. 1.5.0) and compared with available sequences using BLAST in GenBank (National Centre for Biotechnology Information, http://www.ncbi.nlm.nih.gov/BLAST). Representative sequences were deposited in the GenBank database.

\section{Statistical analysis}

Statistical analyses were performed using SigmaPlot version 12 for Windows (Systat. Software Inc., San Jose, CA, USA). The Shapiro-Wilk test was used to test for normal distribution of the data. The Mann-Whitney U test was used to test pathogen distribution according to the sex of foxes. P values less than 0.05 were considered statistically significant. Confidence intervals for proportion were calculated using an online calculator available at http://vassarstats. net/prop1.html. 


\section{Results}

The conducted PCR assay revealed that 79/129 (61.2\%) of the tested spleen samples were positive for Hepatozoon spp. DNA, while 38/129 (29.5\%) samples were found to be positive for the presence of babesial DNA. After analysing the obtained sequences, the presence of two Babesia species was confirmed: B. vulpes in 37/129 samples [28.7\%, 95\% confidence interval (CI): $21.6-37 \%$ ]; and B. canis in $1 / 129$ samples $(0.8 \%, 95 \%$ CI: $0.1-4.3 \%)$. No statistically significant differences in the prevalence of $B$. vulpes infections were detected between females $(10.2 \%, 54 / 128)$ and males $(18.8 \%, 74 / 128)(\mathrm{P}=0.900)$. All samples positive for the presence of DNA of Hepatozoon spp. were identified as H. canis, 79/129 $(61.2 \%, 95 \%$ CI: $52.6 \%-69.2 \%)$. Also, no statistically significant differences in the prevalence of $H$. canis infections were detected between females $(25.6 \%, 55 / 129)$ and males $(35.65 \%, 74 / 129)(\mathrm{P}=0.760)$. Co-infections with B. vulpes and $H$. canis were present in 26/129 (20.2\%) foxes, and their prevalence varied from $15.4 \%$ to $42.9 \%$ at different sampling sites. One animal was co-infected with $B$. canis and $H$. canis $(1 ; 0.8 \%)$. Samples found to be positive for $B$. vulpes DNA originated from nine out of 14 localities, while animals positive for the presence of DNA of $\mathrm{H}$. $\mathrm{ca}$ nis originated from a total of 12 of the 14 locations. The only fox positive for the presence of $B$. canis was shot at the Surčin locality (GenBank accession number: MH702200). Detailed results are presented in Table 1 and Fig. 1.

Table 1

Distribution of foxes positive for, and co-infected with, Hepatozoon canis, Babesia canis and Babesia vulpes by sampling site

\begin{tabular}{|c|c|c|c|c|c|c|c|}
\hline \multirow[b]{2}{*}{ No. } & \multirow[b]{2}{*}{ Locality } & \multirow{2}{*}{$\begin{array}{l}\text { No. of } \\
\text { collected } \\
\text { samples }\end{array}$} & \multicolumn{5}{|c|}{ No. of positive samples } \\
\hline & & & $\begin{array}{c}\text { Hepatozoon } \\
\text { canis } \\
(\%)^{*}\end{array}$ & $\begin{array}{c}\text { Babesia } \\
\text { canis } \\
(\%)\end{array}$ & $\begin{array}{c}\text { Babesia } \\
\text { vulpes } \\
(\%)\end{array}$ & $\begin{array}{c}\text { Co-infection } \\
\text { H. canis- } \\
\text { B. canis }(\%)\end{array}$ & $\begin{array}{l}\text { Co-infection } \\
\text { H. canis- } \\
\text { B. vulpes }(\%)\end{array}$ \\
\hline 1 & Surčin & 29 & $15(51.7)$ & $1(3.4)$ & $15(51.7)$ & $1(3.4)$ & $10(34.5)$ \\
\hline 2 & Obrenovac & 6 & $5(83.3)$ & & $2(33.3)$ & & $2(33.3)$ \\
\hline 3 & Veliko Gradište & 45 & $28(62.2)$ & & $9(20)$ & & 7 (15.6) \\
\hline 4 & Velika Plana & 7 & $6(85.7)$ & & $3(42.9)$ & & $3(42.9)$ \\
\hline 5 & Svilajnac & 13 & $11(84.6)$ & & $3(23.1)$ & & $2(15.4)$ \\
\hline 6 & Negotin & 2 & & & $1(50)$ & & \\
\hline 7 & Despotovac & 1 & $1(100)$ & & & & \\
\hline 8 & Rekovac & 5 & $3(60)$ & & & & \\
\hline 9 & Kraljevo & 3 & $3(100)$ & & $1(33.3)$ & & $1(33.3)$ \\
\hline 10 & Vrnjačka Banja & 5 & $2(40)$ & & & & \\
\hline 11 & Trstenik & 3 & & & $1(33.3)$ & & \\
\hline 12 & Blace & 3 & $1(33.3)$ & & & & \\
\hline 13 & Niš & 5 & $3(60)$ & & $2(40)$ & & $1(20)$ \\
\hline 14 & Bela Palanka & 2 & $1(50)$ & & & & \\
\hline \multicolumn{2}{|c|}{ Total number } & 129 & $79(61.2)$ & $1(0.8)$ & $37(28.7)$ & $1(0.8)$ & $26(20.2)$ \\
\hline
\end{tabular}

*Prevalence 
When the 18S rRNA sequences of $H$. canis obtained in this study were compared with the sequences available in GenBank, they showed $100 \%$ similarity to the sequences obtained in several European countries from different hosts, e.g. from foxes (AY150067, HM212626, GU371448, KM096414, KX887327), from golden jackals (KJ572976, KX712129, KX712123), from dogs (FJ497022, KY247115), and also from $R$. sanguineus (KY197000, KY196999). Representative sequences of $H$. canis obtained in the present study were deposited under accession numbers MH699884-MH699892.

The 18S rRNA sequences of $B$. vulpes obtained in this study (representative sequences were deposited under accession numbers MH699381-MH699396) showed complete mutual similarity, and $100 \%$ identity was evident when compared with previously deposited sequences available in GenBank from foxes living in different countries (e.g. Italy MG451839, Austria KY693667, Slovakia KX761397, Spain KT223483).

\section{Discussion}

In recent years, an increasing number of studies in Europe have pointed out the potential role of foxes as reservoirs for tick-borne pathogens (Tolnai et al., 2015; Hodžić et al., 2018). The present study reports for the first time the occurrence of $B$. canis, B. vulpes and $H$. canis in foxes in the Republic of Serbia. Co-infections of $H$. canis with $B$. vulpes or $B$. canis were also detected and the relatively high prevalence of $H$. canis/B. vulpes co-infection could be explained by similarities in the enzootic cycles of these protozoan agents.

Hepatozoon canis has been detected in many European countries in foxes with a wide range of prevalence (e.g. Portugal $75.6 \%$, Austria 58.3\%, Croatia $23 \%$, Hungary 22.2\%, Bosnia and Herzegovina 38.6\%) (Deždek et al., 2010; Cardoso et al., 2014; Duscher et al., 2014; Hodžić et al., 2015). The prevalence of $H$. canis detected in our study $(61.2 \%)$ is higher than in most of the other regions with the exception of Portugal. The high prevalence of $H$. canis among tested foxes and its wide geographical distribution in Serbia point to the important role of foxes in the epizootiology of this pathogen.

The tick $R$. sanguineus s.l., suggested as the main vector of $H$. canis (Baneth, 2011), is present and has been found to parasitise foxes in Serbia (Tomanović et al., 2013). However, infection of foxes with $H$. canis can be found in regions that are considered free of $R$. sanguineus s.l. (Duscher et al., 2014; Farkas et al., 2014), suggesting a potential role for other tick species in the transmission of $H$. canis. Fairly recently, Giannelli et al. (2013) have suggested that $I$. ricinus is not a competent vector of $H$. canis, while further research is needed to elucidate whether other tick species could be competent vectors of $H$. canis (Najm et al., 2014). Moreover, vertical and oral routes of infection by ingestion 
of infected prey have been proposed as additional transmission pathways that need to be evaluated through further studies (Baneth, 2011).

Rhipicephalus sanguineus s.l. is an ectoparasite of dogs in Serbia (Potkonjak et al., 2016). The presence of $H$. canis has been confirmed by PCR in a healthy dog from the southern part of the country (Gabrielli et al., 2015); however, hepatozoonosis in domestic dogs has not been confirmed so far. The high prevalence of $H$. canis in foxes observed in this study, and the presence of the main vector $R$. sanguineus s.l. which is a mutual ectoparasite of dogs and foxes, suggest the possibility that $H$. canis could also be expected to occur with a higher prevalence in dogs in Serbia. Taking into account the current epizootiological situation regarding $H$. canis, and the fact that $H$. canis is often present in coinfection in ticks with other canine vector-borne pathogens that cause similar clinical signs, veterinarians should pay particular attention to dogs with signs such as fever, anaemia, cachexia, and lethargy which should raise the suspicion of autochthonous canine hepatozoonosis.

In our study, the DNA of $B$. canis was detected only in a single fox $(1 / 129$, $0.8 \%$ ) shot at the Surčin locality. To the best of our knowledge, this is the third molecular confirmation of the presence of $B$. canis in a population of red foxes so far worldwide (Cardoso et al., 2013; Hodžić et al., 2015). Recently, the presence of B. canis (4.2\%) has been confirmed in golden jackals in Serbia. Moreover, $D$. reticulatus, the main vector of $B$. canis, was found to parasitise foxes and jackals in Serbia (Tomanović et al., 2013; Sukara et al., 2018). Since the natural habitats of red foxes and golden jackals overlap (Penezić and Ćirović, 2015), their mutual exposure to the ectoparasite fauna is highly probable. This hypothesis could explain the presence of B. canis in a fox in Serbia. However, further studies are needed to elucidate whether foxes have a relevant role in the epizootiology of $B$. canis or whether the molecular confirmation of its presence was a coincidence.

A relatively high prevalence of $B$. vulpes $(37 / 129,28.7 \%)$ was confirmed among the tested foxes in the present study. Previous research efforts have shown that $B$. vulpes is commonly found in fox populations in Europe (Duscher et al., 2014; Checa et al., 2018). Also, different research groups have reported a relatively high prevalence of $B$. vulpes in foxes from neighbouring countries, e.g. Croatia (5.2\%; Deždek et al., 2010), Bosnia and Herzegovina (31.9\%; Hodžić et al., 2015), Hungary (20\%; Farkas et al., 2015), and Romania (20.1\%; Daskalaki et al., 2018). Although high prevalence of this pathogen has been detected in foxes across Europe, only one clinical case of the disease caused by B. vulpes has been described so far in a fox from Canada (Clancey et al., 2010), indicating the role of foxes as a reservoir for $B$. vulpes.

The geographical distribution of positive samples obtained in the present study indicates that $B$. vulpes is widespread among the fox populations in Serbia and potential vectors of $B$. vulpes (i.e., I. hexagonus, I. canisuga, I. ricinus, $D$. 
reticulatus) are found to parasitise foxes in that country (Tomanović et al., 2013). Although the DNA of $B$. vulpes has been confirmed by PCR only in clinically healthy dogs from Serbia (Gabrielli et al., 2015), the pathogenicity of $B$. vulpes in dogs has been previously confirmed (Solano-Gallego et al. 2016).

Thus, canine babesiosis caused by $B$. vulpes may be a fact in Serbia. Since the treatment of canine babesiosis caused by $B$. vulpes (Baneth, 2018) is different from that used against the most frequent causative pathogen (B. canis) of dog babesiosis in Serbia (Davitkov et al., 2015), we alert veterinarians to the need of identifying the pathogenic species accurately (Solano-Gallego et al., 2016).

In conclusion, the present study is the first report on the occurrence of $B$. canis, B. vulpes, and H. canis in red foxes from the Republic of Serbia. Our findings indicate the importance of foxes in the epizootiology of these blood protozoans and their role as reservoirs. The fact that very often the same species of Babesia and Hepatozoon infect dogs and wild canids, the diseases caused by these pathogens in dogs in Serbia could dangerously emerge. Further research efforts are needed to identify the tick species that are competent vectors of $H$. canis and $B$. vulpes, and to clarify the exact role of other autochthonous wild canids (wolves and jackals) in the epizootiology of these protozoan parasites.

\section{Acknowledgement}

This work was supported by a grant from the Ministry of Education, Science and Technological Development, Republic of Serbia (Project No. 173006)

\section{References}

Baneth, G. (2011): Perspectives on canine and feline hepatozoonosis. Vet. Parasitol. 181, 3-11. Baneth, G. (2018): Antiprotozoal treatment of canine babesiosis. Vet. Parasitol. 254, 58-63.

Baneth, G., Florin-Christensen, M., Cardoso, L. and Schnittger, L. (2015): Reclassification of Theileria annae as Babesia vulpes sp. nov. Parasit. Vectors 8, 1-7.

Birkenheuer, A. J., Correa, M. T., Levy, M. G. and Breitschwerdt, E. B. (2005): Geographic distribution of babesiosis among dogs in the United States and association with dog bites: 150 cases (2000-2003). J. Am. Vet. Med. Assoc. 227, 942-947.

Cardoso, L., Cortes, H. C. E., Eyal, O., Reis, A., Lopes, A. P., Vila-Viçosa, M. J., Rodrigues, P. A. and Baneth, G. (2014): Molecular and histopathological detection of Hepatozoon canis in red foxes (Vulpes vulpes) from Portugal. Parasit. Vectors 7, 2-7.

Cardoso, L., Cortes, H. C. E., Reis, A., Rodrigues, P., Simões, M., Lopes, A. P., Vila-Viçosa, M. J., Talmi-Frank, D., Eyal, O., Solano-Gallego, L. and Baneth, G. (2013): Prevalence of Babesia microti-like infection in red foxes (Vulpes vulpes) from Portugal. Vet. Parasitol. 196, 90-95.

Casati, S., Sager, H., Gern, L. and Piffaretti, J. C. (2006): Presence of potentially pathogenic Babesia sp. for human in Ixodes ricinus in Switzerland. Ann. Agric. Environ. Med. 13, 65-70.

Checa, R., López-Beceiro, A. M., Montoya, A., Barrera, J. P., Ortega, N., Gálvez, R., Marino, V., González, J., Olmeda, Á. S., Fidalgo, L. E. and Miró, G. (2018): Babesia microti-like piro- 
plasm (syn. Babesia vulpes) infection in red foxes (Vulpes vulpes) in NW Spain (Galicia) and its relationship with Ixodes hexagonus. Vet. Parasitol. 252, 22-28.

Ćirović, D. (2000): Morphological variability and biogeographical status of the red fox populations (Vulpes vulpes Linnaeus, 1758) in Vojvodina. MSc Thesis. Faculty of Biology, University of Belgrade.

Clancey, N., Horney, B., Burton, S., Birkenheuer, A., McBurney, S. and Tefft, K. (2010): Babesia (Theileria) annae in a red fox (Vulpes vulpes) from Prince Edward Island, Canada. J. Wildl. Dis. 46, 615-621.

Dantas-Torres, F. and Otranto, D. (2015): Further thoughts on the taxonomy and vector role of Rhipicephalus sanguineus group ticks. Vet. Parasitol. 208, 9-13.

Daskalaki, A. A., Ionică, A. M., Deak, G., Gherman, C. M., D’Amico, G., Păstrav, I. R., Matei, I. A., Domșa, C. and Mihalca, A. D. (2018): Environmental factors influencing the distribution of 'Theileria annae' in red foxes, Vulpes vulpes in Romania. Ticks Tick Borne Dis. 9, 660-664.

Davitkov, D., Vucicevic, M., Stevanovic, J., Krstic, V., Tomanovic, S., Glavinic, U. and Stanimirovic, Z. (2015): Clinical babesiosis and molecular identification of Babesia canis and Babesia gibsoni infections in dogs from Serbia. Acta Vet. Hung. 63, 199-208.

Deždek, D., Vojta, L., Ćurković, S., Lipej, Z., Mihaljević, Ž., Cvetnić, Ž. and Beck, R. (2010): Molecular detection of Theileria annae and Hepatozoon canis in foxes (Vulpes vulpes) in Croatia. Vet. Parasitol. 172, 333-336.

Duscher, G. G., Fuehrer, H.-P. and Kübber-Heiss, A. (2014): Fox on the run - molecular surveillance of fox blood and tissue for the occurrence of tick-borne pathogens in Austria. Parasit. Vectors 7, 521.

Farkas, R., Solymosi, N., Takács, N., Hornyák, Á., Hornok, S., Nachum-Biala, Y. and Baneth, G. (2014): First molecular evidence of Hepatozoon canis infection in red foxes and golden jackals from Hungary. Parasit. Vectors 7, 303.

Farkas, R., Takács, N., Hornyák, Á., Nachum-Biala, Y., Hornok, S. and Baneth, G. (2015): First report on Babesia cf. microti infection of red foxes (Vulpes vulpes) from Hungary. Parasit. Vectors $8,55$.

Gabrielli, S., Otašević, S., Ignjatović, A., Savić, S., Fraulo, M., Arsić-Arsenijević, V., Momčilović, S. and Cancrini, G. (2015): Canine babesioses in noninvestigated areas of Serbia. VectorBorne Zoonotic Dis. 15, 535-538.

Giannelli, A., Ramos, R. A. N., Dantas-Torres, F., Mencke, N., Baneth, G. and Otranto, D. (2013): Experimental evidence against transmission of Hepatozoon canis by Ixodes ricinus. Ticks Tick Borne. Dis. 4, 391-394.

Hodžić, A., Alić, A., Fuehrer, H.-P., Harl, J., Wille-Piazzai, W. and Duscher, G. (2015): A molecular survey of vector-borne pathogens in red foxes (Vulpes vulpes) from Bosnia and Herzegovina. Parasit. Vectors 8, 88.

Hodžić, A., Mrowietz, N., Cézanne, R., Bruckschwaiger, P., Punz, S., Habler, V. E., Tomsik, V., Lazar, J., Duscher, G. G., Glawischnig, W. and Fuehrer, H.-P. (2018): Occurrence and diversity of arthropod-transmitted pathogens in red foxes (Vulpes vulpes) in western Austria, and possible vertical (transplacental) transmission of Hepatozoon canis. Parasitol. 145, 335-344.

Inokuma, H., Okuda, M., Ohno, K., Shimoda, K. and Onishi, T. (2002): Analysis of the 18S rRNA gene sequence of a Hepatozoon detected in two Japanese dogs. Vet. Parasitol. 106, 265-271.

Irwin, P. J. (2009): Canine babesiosis: from molecular taxonomy to control. Parasit. Vectors 2, S4.

James Harris, D. (2016): Naming no names: Comments on the taxonomy of small piroplasmids in canids. Parasit. Vectors 9, 5-6.

Margalit Levi, M., Nachum-Biala, Y., King, R. and Baneth, G. (2018): A survey of Babesia spp. and Hepatozoon spp. in wild canids in Israel. Parasit. Vectors 11, 150.

Millán, J., Proboste, T., Fernández de Mera, I. G., Chirife, A. D., de la Fuente, J. and Altet, L. (2016): Molecular detection of vector-borne pathogens in wild and domestic carnivores and their ticks at the human-wildlife interface. Ticks Tick Borne Dis. 7, 284-290. 
Miró, G., Checa, R., Paparini, A., Ortega, N., González-Fraga, J. L., Gofton, A., Bartolomé, A., Montoya, A., Gálvez, R., Mayo, P. P. and Irwin, P. (2015): Theileria annae (syn. Babesia microti-like) infection in dogs in NW Spain detected using direct and indirect diagnostic techniques: clinical report of 75 cases. Parasit. Vectors 8, 217.

Najm, N.-A., Meyer-Kayser, E., Hoffmann, L., Herb, I., Fensterer, V., Pfister, K. and Silaghi, C. (2014): A molecular survey of Babesia spp. and Theileria spp. in red foxes (Vulpes vulpes) and their ticks from Thuringia, Germany. Ticks Tick Borne Dis. 5, 386-391.

Penezić, A. and Ćirović, D. (2015): Seasonal variation in diet of the golden jackal (Canis aureus) in Serbia. Mammal Res. 60, 309-317.

Penzhorn, B. L. (2011): Why is Southern African canine babesiosis so virulent? An evolutionary perspective. Parasit. Vectors 4, 51.

Petra, B., Josipa, K., Renata, B. R. and Vladimir, M. (2018): Canine babesiosis: Where do we stand? Acta Vet. Brno 68, 127-160.

Plumer, L., Davison, J., Saarma, U. and Cameron, E. Z. (2014): Rapid urbanization of red foxes in Estonia: distribution, behaviour, attacks on domestic animals, and health-risks related to zoonotic diseases. PLoS One 9, 1-15.

Potkonjak, A., Gutiérrez, R., Savić, S., Vračar, V., Nachum-Biala, Y., Jurišić, A., Kleinerman, G., Rojas, A., Petrović, A., Baneth, G. and Harrus, S. (2016): Molecular detection of emerging tick-borne pathogens in Vojvodina, Serbia. Ticks Tick Borne Dis. 7, 199-203.

Solano-Gallego, L., Sainz, Á., Roura, X., Estrada-Peña, A. and Miró, G. (2016): A review of canine babesiosis: the European perspective. Parasit. Vectors 9, 336.

Sukara, R., Chochlakis, D., Ćirović, D., Penezić, A., Mihaljica, D., Ćakić, S., Valčić, M., Tselentis, Y., Psaroulaki, A. and Tomanović, S. (2018): Golden jackals (Canis aureus) as hosts for ticks and tick-borne pathogens in Serbia. Ticks Tick Borne Dis. 9, 1090-1097.

Theodoropoulos, G., Gazouli, M., Ikonomopoulos, J. A., Kantzoura, V. and Kominakis, A. (2006): Determination of prevalence and risk factors of infection with Babesia in small ruminants from Greece by polymerase chain reaction amplification. Vet. Parasitol. 135, 99-104.

Tolnai, Z., Sréter-Lancz, Z. and Sréter, T. (2015): Spatial distribution of Anaplasma phagocytophilum and Hepatozoon canis in red foxes (Vulpes vulpes) in Hungary. Ticks Tick Borne Dis. 6, 645-648.

Tomanović, S., Radulović, Ž., Ćakić, S., Mihaljica, D., Sukara, R., Penezić, A., Burazerović, J. and Ćirović, D. (2013): Tick species (Acari: Ixodidae) of red foxes (Vulpes vulpes) in Serbia. In: 2nd Int. Symp. Hunting, 'Modern aspects of sustainable management of game population'. University of Novi Sad, Faculty of Agriculture, Novi Sad. pp. 229-235. 